\title{
ШАТЫРТАС: НОВЫЕ ОТКРЫТИЯ НАСКАЛЬНОЙ ЖИВОПИСИ В ЮГО-ВОСТОЧНОМ КАЗАХСТАНЕ (предварительная публикация)
}

\section{(C) 2020 г. Алексей Евгеньевич Рогожинский ${ }^{1}$}

${ }^{1}$ к.и.н., ведущий научный сотрудник, Институт археологии им. А.Х. Маргулана, г. Алматы, Казахстан. E-mail: alexeyro@hotmail.com

Аннотация. В 2019 г. автором обнаружена в горах Киндыктас (Шуский р-н Жамбылской обл., Юго-Восточный Казахстан) ранее неизвестная группа памятников - выполненные минеральными красками наскальные изображения под скальными навесами и в небольших гротах. В настоящее время обнаружено 14 пунктов с росписями; они сосредоточены на коротком участке долины Сарыбулак и по местному названию подобных скальных полостей получили общее наименование Шатыртас. Росписи многих гротов и навесов характеризуются сходством технических приемов исполнения рисунков и репертуара: орнаментальные геометрические фигуры, зооморфные и антропоморфные изображения. На основании аналогий с орнаментацией расписной керамики анауской культуры юга Туркменистана и поселения Саразм в Таджикистане обосновывается датировка древнейших наскальных рисунков: конец периода среднего - начало периода позднего энеолита (позднее Намазга II - раннее Намазга III) и ранняя бронза (Намазга IV). Небольшая часть росписей отличается иным репертуаром (всадники, олень и др.) и датируются средневековым периодом.

Ключевые слова: археология, горы Киндыктас, наскальная живопись, грот, скальный навес, энеолит, ранняя бронза, расписная керамика

\section{ШАТЫРТАС: ОНТУСТІК-ШЫҒЫС ҚАЗАҚСТАНДАҒЫ ЖАНА АШЫЛҒАН ЖАРТАСТАРДАҒЫ СУРЕТТЕР (алдын ала жариялау)}

\section{Алексей Евгеньевич Рогожинский ${ }^{1}$}

${ }^{1}$ ЖҒҚ, т.ғ.к., Ә.Х. Марғұлан атындағы Археология институты, Алматы қ., Қазақстан,. E-mail: alexeyro@hotmail.com

Аннотация. 2019 ж. Кіндіктас тауларында (Шу ауданы, Жамбыл облысы, Оңтүстік-Шығыс Қазақстан) осы уақытқа дейін белгісіз болып келген ескерткіштер тобы - құздың асылмалы жақтарына және шағын үңгірлерге минералды бояулармен салынған жартасқа салынған кескіндер табылды. Қазіргі уақытта өрнектерімен 14 орны табылып, олар Сарыбұлақ жазығының қысқа аумағында шоғырланған және жергілікті сондай құзды жолақтың атауына сәйкес Шатыртас деген жалпы ортақ атаумен аталды. Көптеген үңгірлер мен құламалылардағы өрнекті суреттердің салынуы мен репертуарының технкалық орындалуындағы ұқсастықтарымен сипатталады: өрнекті геометриялық пішіндер, зооморфтық және адампішінді кескіндер. Түркменстанның оңтүстігі мен Тәжікстандағы Саразм елдімекеніндегі анау мәдениетінің боялған қыш бұйымдарындағы оюлардың баламасы негізінде ежелгі жартас суреттерді мерзімдеуге негізделген: энеолиттің орта кезеңінің соңы - кейінгі кезеңінің басы (кейінгі Намазга II - ерте Намазга III) және ерте қола (Намазга IV) дәуірі. Өрнектердің аз ғана бөлігі өзгеше репертуармен ерекшеленеді (атты адамдар, бұғы және т.б.) және ортағасырлар кезеңі. 
Түйін сөздер: археология, Кіндіктас таулары, тасқа салынған суреттер, үңгір, аспалы құз, энеолит, ерте қола, боялған қыш

\title{
SHATYRTAS: NEW DISCOVERIES OF THE ROCK PAINTINGS IN SOUTH-EAST KAZAKHSTAN (preliminary publication)
}

\author{
Alexey E. Rogozhinskiy ${ }^{1}$ \\ ${ }^{1}$ Candidate of Historical Sciences, Leader scientific researcher, A.Kh. Margulan \\ Archeology Institute. Almaty, Kazakhstan, E-mail: alexeyro@hotmail.com
}

\begin{abstract}
In 2019, the author discovered a previously unknown group of monuments in the Kindyktas Mountains (South-East Kazakhstan) - paintings under rock shelters and in grottoes. Currently, 14 shelters and grottoes with paintings have been discovered; they are concentrated within a short section of the Sarybulak valley, and were designated as Shatyrtas according to the local name for such rocky cavities. The paintings of many grottoes and shelters are characterized by the similarities of technique for the execution of images as well as repertoire including ornamental geometric figures, zoomorphic and anthropomorphic images. Based on the analogies with ornamentation of the painted pottery of the Anau culture (Turkmenistan) and Sarazm settlement (Tajikistan), the dating of the oldest paintings is justified: the end of the Middle period - the beginning of the Late Eneolithic (later Namazga II - early Namazga III) and Early Bronze Age (Namazga IV). A small number of paintings shows a different repertoire (horsemen and deer, etc.) and dates from the Medieval period.

Keywords: archaeology, Kindyktas Mountains, rock paintings, grotto, rock shelters, Eneolithic, Early Bronze Age, painted pottery
\end{abstract}

\section{Введение}

В 2019 г. по программе научного проекта «Разработка модели коммуникаций населения Центральной Азии в древности и средневековье: взаимодействие традиций и диалог культур» (руководитель проекта - к. и. н. В. А. Новоженов, РГКП Государственный музей «Центр сближения культур»; ИРН проекта АР 05131564) автором проводились поисковые работы в Кордайском и Шуском районах Жамбылской области. В ходе археологической разведки вдоль западного склона гор Киндыктас (северо-западный отрог Иле Алатау в южной оконечности Шу-Илейского водораздела) в долине Сарыбулак обнаружены ранее не известные памятники наскального искусства - группа скальных навесов и гротов с росписями, которым посвящена настоящая статья. В публикациях специалистов, в прежние годы об- следовавших данный географический район, памятники такого вида не упоминаются.

Локализация и характеристика

\section{памятников}

Ущелье Сарыбулак входит в систему эрозионных долин субширотного простирания на западном склоне возвышенности Киндыктас, обрамляющей на северо-востоке долину р. Шу. В среднем течении долина Сарыбулак имеет вид каньона, выработанного в коренных породах гранитов и песчаников. Водно-ветровая эрозия способствовала формированию здесь живописного ландшафта, особенностью которого является большое количество скальных полостей разной величины - неглубоких гротов и навесов. На протяжении 5-7 км долина часто меняет главное направление (северо-восток - юго-запад), и основная группа обнаруженных па- 
мятников приурочена к сильно рассеченному правому склону ущелья в зоне большого меандра. Глубокое ложе долины на этом участке имеет каменистое основание, в узкой пойме ручья Сарыбулак и вдоль русел боковых притоков местами встречаются древесно-кустарниковые заросли (дикая яблоня, ива и др.). На сохранившихся поверхностях древней террасы отмечены многочисленные остатки древних каменных сооружений, в разной мере скрытых склоновыми отложениями, а также руины зимовок XIX - начала XX в.; выше и ниже каньона на расширенных участках долины с пологими склонами располагаются современные животноводческие хозяйства.

Полости с красочными рисунками и петроглифами обнаружены преимущественно на правом склоне ущелья южной экспозиции, на подсолнечной стороне; лишь один навес с росписями найден на левом борту каньона. К настоящему времени обследовано 13 пунктов с наскальной живописью и один навес с выбитыми рисунками, которые рассредоточены на отрезке долины протяженностью около 4 км. Один из самых крупных навесов с впечатляющими рисунками находится на территории крестьянского хозяйства «Атамекен» Мурата Дуйдейбаева (рис. 1, 3), который и представил нам первый памятник с полихромными росписями, как оказалось, давно известный местным жителям. Старожил указал также на скалистую вершину близлежащего увала, которая отличается особенно живописным нагромождением крупных каменных глыб, образующих множество просторных полостей и навесов, связанных между собой ходами. Эта вершина с давних пор об- любована окрестной молодежью как место отдыха, праздничных гуляний и получила название «Шатыртас» («каменный шатер»). В ходе тщательного осмотра скал здесь нам удалось обнаружить еще пять пунктов с красочными рисунками, о которых старожилу ранее не было известно. Дальнейший поиск в долине Сарыбулак позволил отыскать и другие похожие полости с наскальной живописью, которым присвоено то же условное название Шатыртас с дополнительным цифровым индексом.

Первая группа памятников с росписями (рис. 1, 1), компактно располагающихся возле вершины Шатыртас, включает шесть местонахождений: Шатыртас 1-5 (на одноименной вершине) и Шатыртас 6 (вблизи крестьянского хозяйства). Второе обособленное скопление подобных объектов обнаружено в 3,5 км выше по долине - Шатыртас 7-13, и еще в 500 м выше по каньону находится грот Шатыртас 14. Однако, несмотря на проведенную тщательную разведку, не исключается вероятность обнаружения здесь и других объектов с наскальной живописью.

По морфологии субстрата скальных полостей, использованных для создания рисунков, найденные памятники можно разделить на две разновидности: навесы/ниши и гроты. К первым относятся Шатыртас 1-3, 5, 7-10, 12 и 13; это выветренные полости в виде небольших ниш и навесов или глыбы с отрицательными поверхностями, на которые наносились рисунки. Вторая разновидность (Шатыртас 4, 6, 11 и 14) представлена глубокими полостями (до 5 м) с широким устьем и сравнительно невысоким сводом (до 0,5-0,8 м; в Шатыртас 6 - более 1 м); рисунки разме- 
Pогожинский A.E. Шатыртас: новые открытия наскальной живописи в Юго-Восточном Казахстане
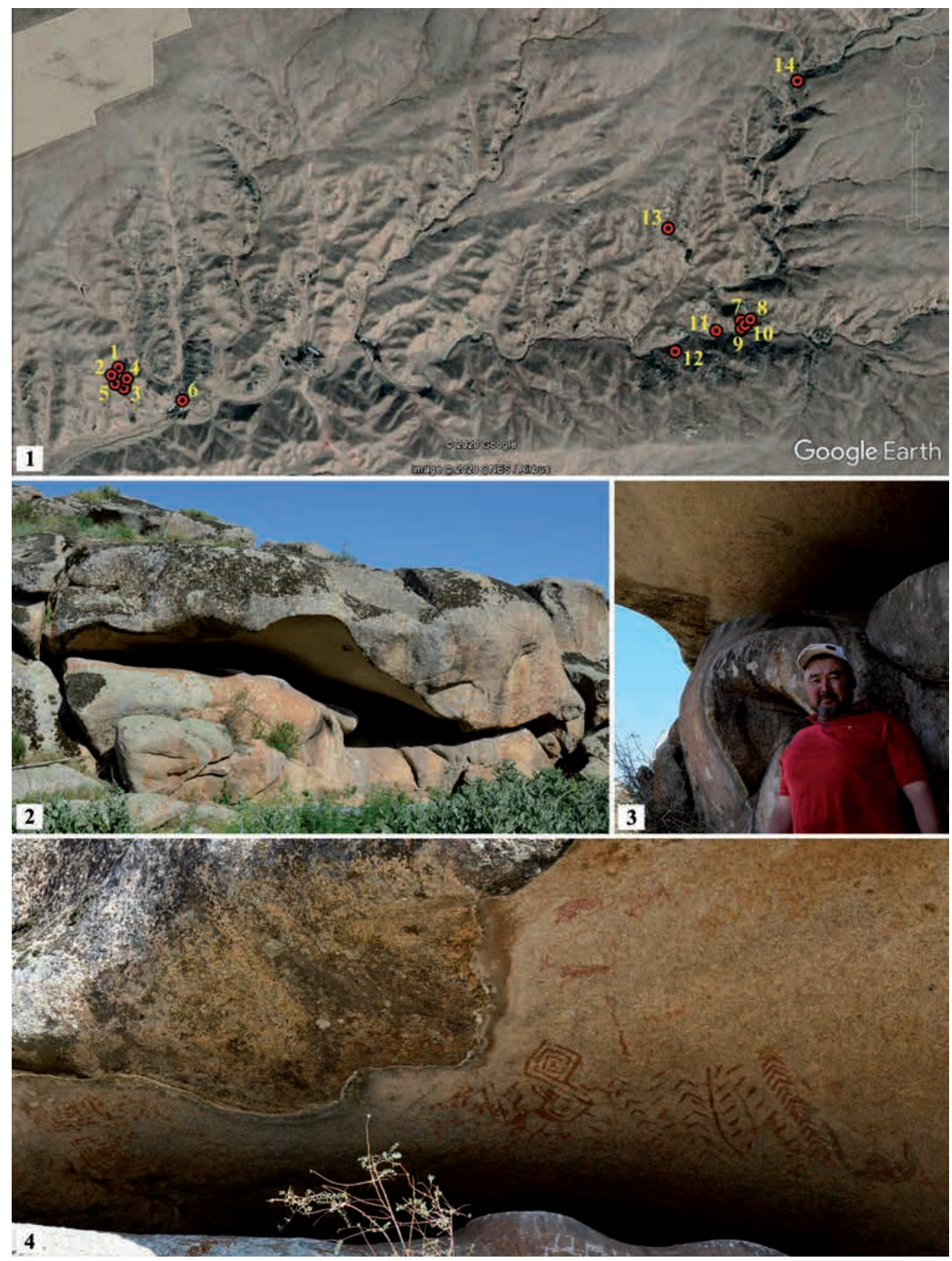

Рис. 1. Памятники наскальной живописи долинь Сарьгулак:

1 - местонахождение скальных навесов и гротов Шатыртас 1-14;

2-4 - общий вид грота Шатыртас 6 и панно с росписями. Фото автора

Fig. 1. Paintings of the Sarybulak valley: 1 - localization of rock shelters and grottoes Shatyrtas 1-14; 2-4-general view of the Shatyrtas 6 grotto and panel with paintings. Author's photo 


\section{ҚАЗАҚСТАН АРХЕОЛОГИЯСЫ № 3 (9) 2020}

щаются в основном на сводах, иногда - на боковых поверхностях внутри гротов или на привходовых участках. В отличие от навесов, подход к ко-
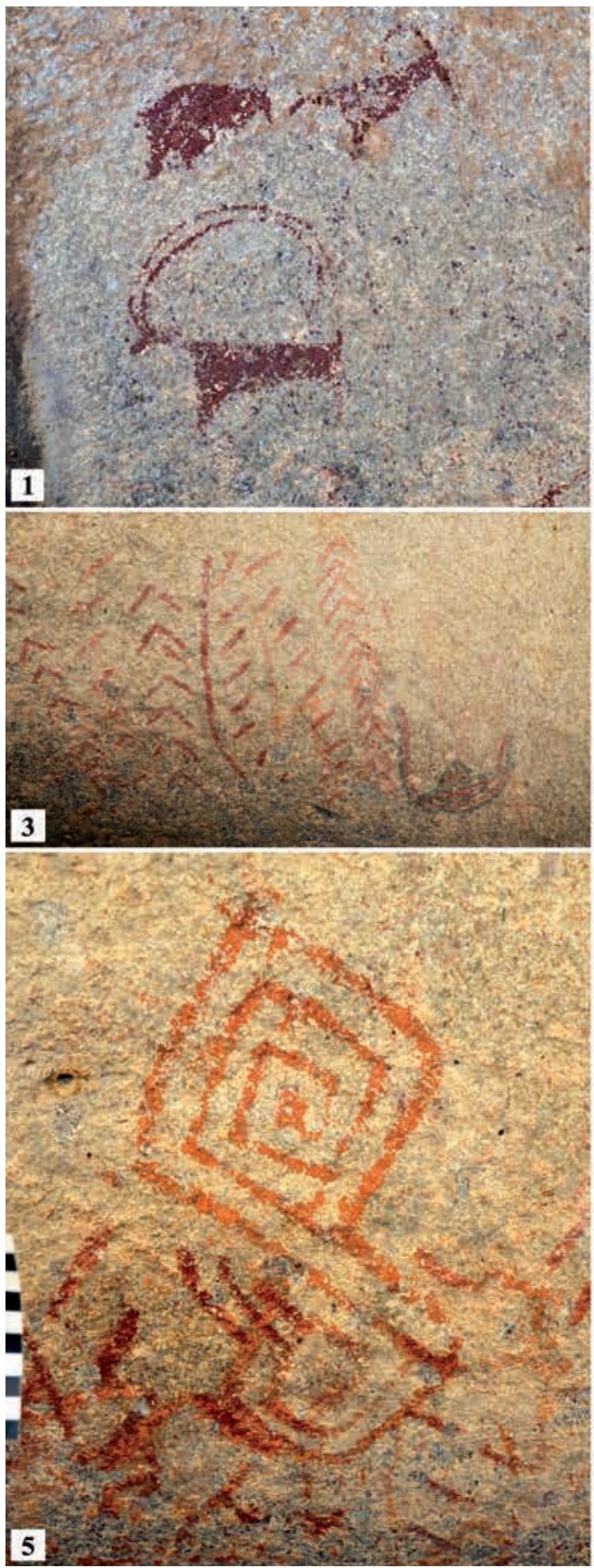

торым открытый, а многие рисунки доступны обзору снаружи, росписи в гротах можно рассматривать, только находясь внутри, лежа на спине
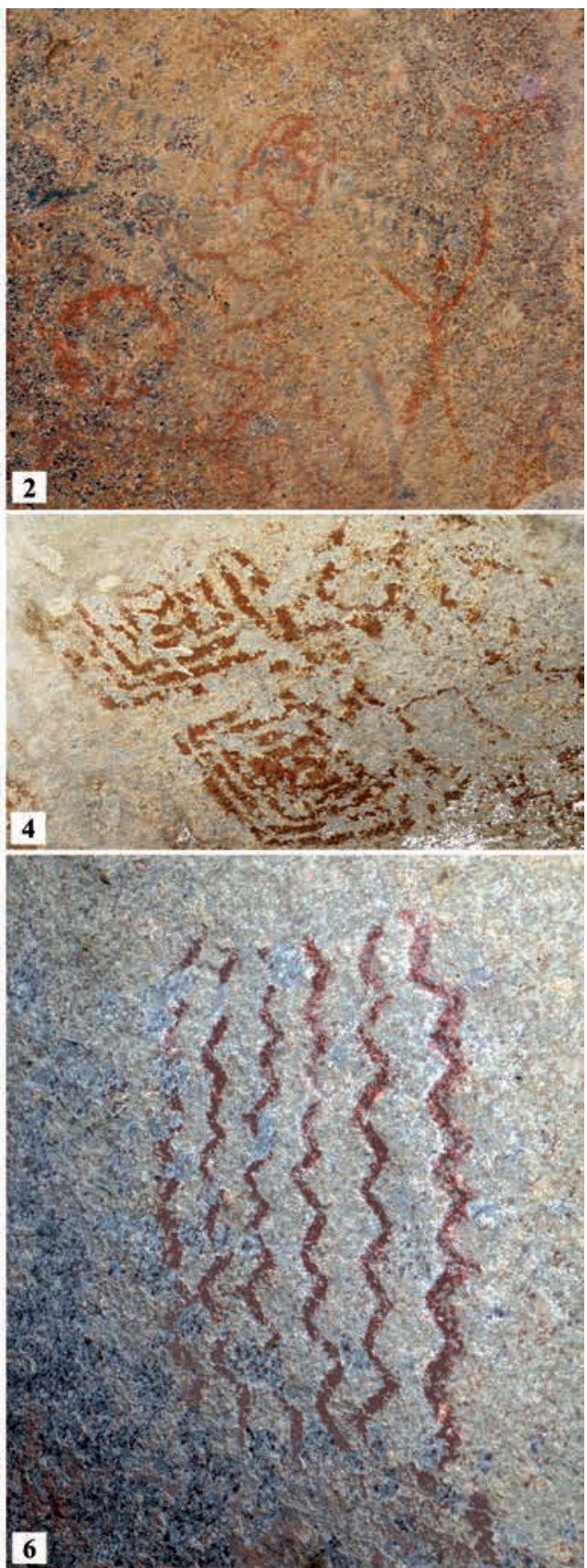

Рис. 2. Росписи грота Шатыртас 6. Фото автора

Fig. 2. Paintings of the Shatyrtas 6 grotto. Author's photo 
или сидя, запрокинув голову; лишь отдельные фигуры видимы снаружи через устье гротов. Такие специфические особенности памятников вызвали определенные трудности при документировании наскальной живописи, которое необходимо продолжить в дальнейшем с применением дополнительного искусственного освещения и соответствующей фототехники (практически все публикуемые в статье фотографии росписей обработаны в программе Photoshop и не передают истинные цвета красочных рисунков). Кроме того, часть рисунков в гротах покрыта тонкой натечной пленкой матового цвета, из-за которой не удается выявить точные контуры отдельных изображений. В ряде случаев заметно разрушение рисунков в результате десквамации шелушения поверхности.

Рисунки выполнены минеральной краской преимущественно красного цвета темных и светлых тонов, но встречаются изображения, сделанные пигментом светло-коричневого, черного и даже белого цвета, причем отдельные из них - бихромные. В отдельных случаях заметно, что рисунки подновлялись или дополнялись новыми деталями спустя некоторое время после их создания. Иногда можно видеть красочные линии другого оттенка, нанесенные поверх выцветших контуров или дополняющие первоначальный рисунок новыми деталями. На панно в гроте Шатыртас 6 наблюдаются случаи перекрывания одних рисунков другими; на своде грота Шатыртас 14 некоторые рисунки ярко-красного цвета, видимо, подновлялись или дорисовывались пигментом бордового оттенка, и здесь тоже есть палимпсесты.
В репертуаре росписей преобладают комбинированные символические фигуры, состоящие из ограниченного набора геометрических элементов (линий, точек, окружностей, треугольников, квадратов), соединяющихся в орнаментальные мотивы и композиции, но помимо этого встречаются антропоморфные и зооморфные изображения. Возможно, отдельные группы рисунков объединены в смысловые композиции, в которых символические фигуры чередуются с изображениями животных и людей. В декоре Шатыртас 6, 11-14 присутствуют в основном или исключительно орнаментальные фигуры и знаки; здесь же насчитывается наибольшее количество изображений: до 10-30 отдельных фигур.

\section{Описание памятников}

Навес Шатыртас 1 (рис. 3, 2) существенно отличается от всех других обследованных памятников комплекса: это наземное естественное укрытие на западном склоне увала, образовавшееся под глыбой, которая опирается нижним краем на поверхность склона, а верхним - на выступ соседней скалы. У северного входа сквозной полости замечены остатки полуразрушенных стен, сложенных из некрупных камней. Внутри укрытия снизу на поверхности глыбы, обращенной к скале, различается более 10 изображений, нанесенных красной краской. Среди них - схематичные силуэты 3-4 всадников на лошадях, козлов, оленя, два знака типа «птичья лапка» и крест, а также изящная фигурка лошади в прыжке или беге, выполненная контуром в реалистичной манере. Красочное изображение лошади отличается от других рисунков более ярким оттенком; над ней 

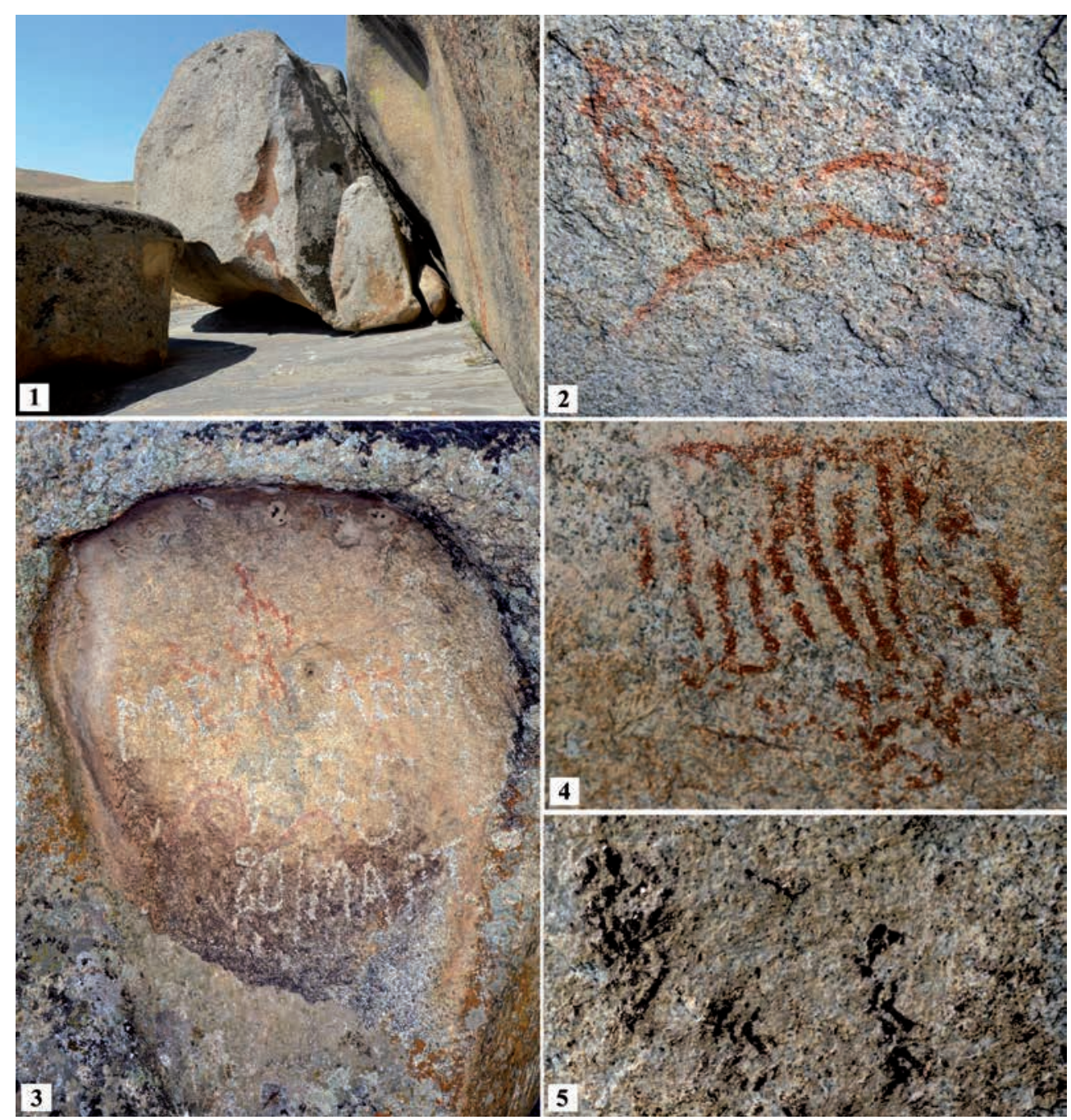

Рис. 3. Росписи скальных навесов: 1 - Шатыртас 3 и 4; 2 - Шатыртас 1; 3 - Wатыртас 3; 4, 5 - Шатыртас 2. Фото автора

Fig. 3. Paintings of rock shelters: 1 -Shatyrtas 3 and 4; 2 - Shatyrtas 1; 3 -Shatyrtas 3; 4, 5 -Shatyrtas 2. Author's photo

едва заметна фигура всадника с разведенными в стороны руками, которая явно дорисована позже - той же красновато-коричневой краской, которой сделаны схематичные рисунки всадников и зверей. Все рисунки небольших размеров (10-25 см), чем они также отличаются от многих росписей других навесов долины Сарыбулак. Вероятно, изображения всадников могут датироваться средневековым периодом или даже позже; контурная фигура лошади, по-видимому, более ранняя.

Шатыртас 2 представляет собой просторную полость с куполообразным сводом (высота до 2 м, длина более 3 м). Перед входом на вертикальной поверхности небольшой ниши сохранилось крупное символическое изображение $(17 \times 20$ см), нарисованное красно-коричневой краской (рис. 3,4$)$. Внутри навеса на боковой стене обособленно друг от друга нахо- 
дятся еще две группы рисунков: орнаментальная фигура, состоящая из субпараллельных вертикальных зигзагов (рис. 3, 5), и изображения следующих друг за другом животных с поднятыми кверху хвостами (собаки?). Животные нарисованы краской более светлого оттенка, чем остальные рисунки.

Шатыртас 3 - небольшая ниша овальной формы на вертикальной грани глыбы, которая также лежит на западном склоне увала вблизи эпонимного скального укрытия без рисунков, в 30 м от навеса Шатыртас 2. Ниша находится на высоте 1,5-2,0 м от уровня широкой ровной скальной поверхности, служившей импровизированной «танцплощадкой» (рис. 3, 1) для отдыхавшей здесь местной молодежи, поэтому на окружающих скалах много процарапанных и выбитых «автографов», в том числе в самой нише поверх красочных рисунков. В центре ниши сохранились три отчетливо видимые схематичные антропоморфные фигуры, выполненные темно-красной краской, а ниже - контурное изображение горного козла в реалистичной манере, сделанное краской бордового цвета (рис. 3,3$)$. По стилю и пропорциям рисунок козла напоминает фигурку лошади из Шатыртас 1 , но дорисован у края ниши, по-видимому, позже фигурок людей.

Грот Шатыртас 4 находится в 2 м от описанных рисунков; это неглубокая полость в основании глыбы, ограничивающей с севера поверхность «танцплощадки». На своде грота, сильно поврежденном десквамацией, частично сохранилось только одно изображение, выполненное краснокоричневой краской: радиально расходящиеся четыре линии (7 см).

Шатыртас 5 - высокий навес в привходовой части сквозной полости еще одной глыбы, лежащей на склоне ниже «танцплощадки». Здесь сохранились лишь пятна каких-то красочных изображений темно-красного цвета.

Грот Шатыртас 6 (рис. 1, 2-4) особо выделяется своими размерами, монументальностью и разнообразием украшающих его свод росписей. Полость находится в устье примыкающей к ущелью Сарыбулак эрозионной долины, в верховье которой берут начало родники, снабжающие водой ближние фермерские хозяйства. Устье грота возвышается всего на метр над поверхностью долины, над входом нависает каменный козырек высотой 2,0-4,5 м; ширина полости 8,5 м, глубина более 3 м. Нижняя поверхность грота наклонная, сильно отполирована; на ней выбито много современных надписей, но древние рисунки на своде и козырьке подобных повреждений не имеют. Внутри грота на своде есть много красочных изображений разной сохранности, но основное панно образуют рисунки, нанесенные вдоль края нависающего над входом козырька и хорошо видимые от подножья скалы.

Рисунки выполнены преимущественно охрой красного цвета разных оттенков, а также черным и в одном случае - белым пигментом; есть полихромные изображения, для которых применялась краска двух цветов. В ряде случаев изображения разного цвета перекрывают друг друга, а фигуры ориентированы по-разному. Несомненно, росписи создавались не одновременно, панно на козырьке и на своде неоднократно обновлялось и дополнялось другими изображениями, однако очередность нанесения рисунков и даже общее количество фигур сложно установить из-за сохранности рисунков. 
Внутри грота на своде можно различить несколько черных красочных фигур: широкую сплошную линию, схематичную фигуру человека (?) и над ней - длинную линию, состоящую из цепочки двойных удлиненных пятен. Видимо, позже нанесены рисунки, сделанные красной и красно-коричневой краской, причем некоторые - поверх черных пятен или вписаны между ними (рис. 2, 2). Среди красных рисунков также различаются две схематичные антропоморфные фигуры (одна из них изображает стрелка с маленьким луком в руке) и окружность, внутри которой по периметру нарисован непрерывный ряд силуэтных треугольников. Правее нее - орнаментальная фигура в виде соединенных асимметричных ромбов с линиями-выступами на вершинах; край фигуры частично перекрывает контурное изображение животного, следом за которым - силуэтная фигура лошади (?). В глубине грота на своде проявляются еще две небольшие окружности, разделенные на равные секторы тремя радиальными линиями; рядом - орнаментальная комбинация из двух треугольников и пары полуовалов по краям, соединенных последовательно. Все эти изображения можно видеть не иначе как находясь внутри грота.

Непосредственно над входом, на козырьке, представлена целая группа простых и сложных очень крупных (до 30-40 см) символических изображений, орнаментальных мотивов, а также рисунков животных и человека (рис. 1, 4). Верх козырька на максимальной высоте занимает анималистический сюжет: ползущая змея и две собаки, преследующие кабана и козла (рис. 2, 1). Ниже, образуя фриз на видимой с площадки перед гротом поверхности, располагается справа налево следующий ряд изображений. Над устьем грота - контурная фигура в виде угла с ажурными лопастями; три пары субпараллельных волнообразных линий красно-коричневого цвета, вдоль левого края которых, повторяя контур зигзагов, дополнительно нарисованы линии белого цвета (рис. 2, б). Выше и левее находится еще одна крупная бихромная фигура, напоминающая водоплавающую птицу со сложенным крылом и длинной шеей; основные линии фигуры выполнены черной и темно-красной краской (рис. 2, 3), справа внизу - две пересекающиеся линии красного цвета; возможно, они дорисованы позже. Над заостренным выступом-«крылом» едва просматривается фигура человека с большой округлой головой и поднятыми вверх руками, вероятно, тоже нарисованная позже полихромного рисунка.

Левее изображения «птицы» находится ряд однотипных фигур: три вертикальные «елочки» из перевернутых шевронов (они нарисованы поверх «головы» длинношеей «птицы»); сплошные линии, чередующиеся с колонками нарисованных друг над другом коротких наклонных штрихов. Разные изображения выполнены краской бурого цвета или красного оттенка. Светлой красной краской также изображена сложная фигура в виде двухполюсной спирали, образованной ломаной под прямым углом линией (рис. 2, 5). В верхней части фигуры линия имеет три полных оборота и заканчивается небольшим ромбовидным утолщением в форме змеиной головы; в нижней части линия делает два полных оборота и закругленное окончание - «хвост змеи». Нижняя часть двуспиральной фигуры 
перекрывается несколькими короткими поперечными линиями бурого цвета. Крайним слева изображением является наклонная пунктирная линия, сходная по цвету пигмента со спиралевидной фигурой и остатками еще каких-то рисунков, заметных на данном участке панно; длинные и короткие бурые линии здесь также перекрывают росписи красного цвета.

Завершает фриз слева еще одна группа изображений, к сожалению, частью поврежденных десквамацией поверхности и карбонатными натеками от края козырька. Выделяются две расположенные одна над другой похожие фигуры: в центре каждой из них находится залитый краской квадрат (или ромб с прямыми углами, развернутый углом вниз), который трижды обведен широкими линиями, образующими вписанные одна в другую рамки (рис. 2, 4). Правее верхнего изображения просматривается контур рисунка в форме прямого креста с точкой в центре; ниже него - линия зигзага или ступенчатой фигуры. Все рисунки выполнены однотонной темно-красной краской. У левого края карниза, обособленно от других рисунков, находится группа зооморфных изображений: три изящные фигурки хищников, следующих один за другим (их фигуры развернуты головой к краю карниза); у нижнего животного показан закинутый к спине загнутый крючком хвост (собака?). Правее верхнего хищника слабо просматривается размытое изображение козла. Рисунки выполнены темно-красной краской.

Как уже говорилось, вторую обособленную группу памятников долины Сарыбулак образуют навесы и гроты Шатыртас 7-13 и 14, которые обнаруживают как сходство, так и отличие с описанными выше. Например, помимо красочных рисунков, здесь есть выбитые на камне изображения.

Навес Шатыртас 9 отличается своей причудливой скульптурной формой, напоминающей в профиль и анфас фигуру хищной птицы с приподнятыми крыльями или кобры с развернутым капюшоном. На выветренных нижних поверхностях навеса росписей не обнаружено, но есть выбитые рисунки, которые занимают две вертикальные плоскости под «капюшоном», покрытые коричневой патиной. Рисунки нанесены неглубокой выбивкой и по цвету «пустынного загара», покрывающего сколы, выглядят довольно древними. Различается крупная фигура, возможно, лучника с головой в виде двух концентрических окружностей; слева от нее угадываются силуэты двух животных (козел и хищник). На второй плоскости выбиты еще два изображения козлов - иные по стилю и цвету патины. Датировка петроглифов вызывает затруднения.

Вблизи этого навеса росписи обнаружены на поверхности глыбы Шатыртас 10, нависающей над дном долины; у подножия скалы заметны остатки примыкающей к ней полукругом небольшой каменной постройки. На покрытой коричневой патиной поверхности монолита, на высоте около 2 м от земли, сохранились две антропоморфные фигуры, выполненные краской темно-красного цвета. Схематичные изображения выглядят как соединенные узкой линией две человеческие фигуры с разведенными в стороны руками и ногами (общая высота 65 см), размещенные одна над другой. Правее на скале имеются еще красочные линии и пятна - остатки не сохранившихся изображений.

Над двумя описанными группами рисунков, на вершине той же 
скалы, расположенной на изгибе каньона, находятся еще два навеса с росписями и петроглифами - Шатыртас 7 и 8. Две лежащие рядом глыбы - части расколовшегося монолита имеют сходную форму и размеры; неглубокие полости открыты с западной стороны, и рисунки доступны обзору снаружи с небольшой площадки возле скалы (рис. 4,1$)$. Многие участки внутренней поверхности навесов повреждены десквамацией, кое-где заметны следы размытых красочных рисунков. В Шатыртас 7 на вертикальной широкой поверхности различается крупная контурная фигура животного, выполненная светло-коричневой краской, а также неясные следы росписей темно-красного цвета. Кроме того, выбивкой здесь намечены две фигуры рогатых животных (быки?). Лучше различимы росписи навеса Шатыртас 8: частично поврежденная сколом сложная комбинация из пересекающихся под углом линий и точек внутри треугольных сегментов и ромбов (орнаментальный фриз, сверху и снизу обведенный линиями, и справа - двумя линиями-разделителями), левее нее - горизонтальная изогнутая дугой линия и группа точек над ней (рис. 4,2$)$. Остатки еще каких-то рисунков заметны на своде навеса. Все росписи выполнены краской темнокрасного цвета.

Примечательная серия росписей обнаружена в гроте Шатыртас 11, расположенном в 130 м от Шатыртас 9 ниже по долине. Глыба имеет выразительную скульптурную форму и венчает высокую скалу с отвесными стенами; лишь с одной стороны есть удобный подход к довольно широкому входному отверстию сквозной полости (рис. 5, 1). Над входом слабо различимо небольшое изображение какого-то знака, сделанное тонкой линией темно-красного цвета. Внутри грота росписи нанесены на узкую грань под сводом справа от входа и на низком потолке; высота свода здесь не превышает полуметра, так что рисунки на потолке можно видеть только лежа на отполированной поверхности пола. Каменный свод разделен продольным выступом на две неравные части - «внутреннюю», в глубине грота, и «внешнюю», нависающую над противоположным от входа отверстием грота. Длина полости между двумя входными отверстиями составляет около 3 м, высота 0,5-0,8 м. Несколько пятен и линий росписей слабо различаются у края свода с «внешней» стороны. Значительно лучше сохранились рисунки в глубине грота: две антропоморфные фигуры и орнаментальный мотив под сводом, а также крупное изображение быка, корпус которого украшает (рис. 5, 2, 3) ряд повторяющихся орнаментальных элементов - чередующиеся пары лент с зубчатым оформлением одной из сторон, двух- и трехступенчатые «пирамидки», образующие равноконечный крест вокруг квадрата в центре фигуры. К сожалению, левая сторона рисунка сохранилась хуже, но здесь тоже просматриваются зубчатые ленты, симметрично украшающие эту часть фигуры. Все изображения грота выполнены краской бурого цвета.

Навес с росписями Шатыртас 12 находится в 220 м ниже по долине на левом борту каньона, напротив устья короткой эрозионной долины. Навес находится на высоте около 10 м от ложа долины, но некоторые изображения, сделанные яркой красной краской, хорошо видны издали (рис. 4,3 , 4). Полость имеет глубину более $1 \mathrm{M}$, длину до 5 м и высоту около 2,0 ме- 
Pогожинский A.E. Шатыртас: новые открытия наскальной живописи в Юго-Восточном Казахстане
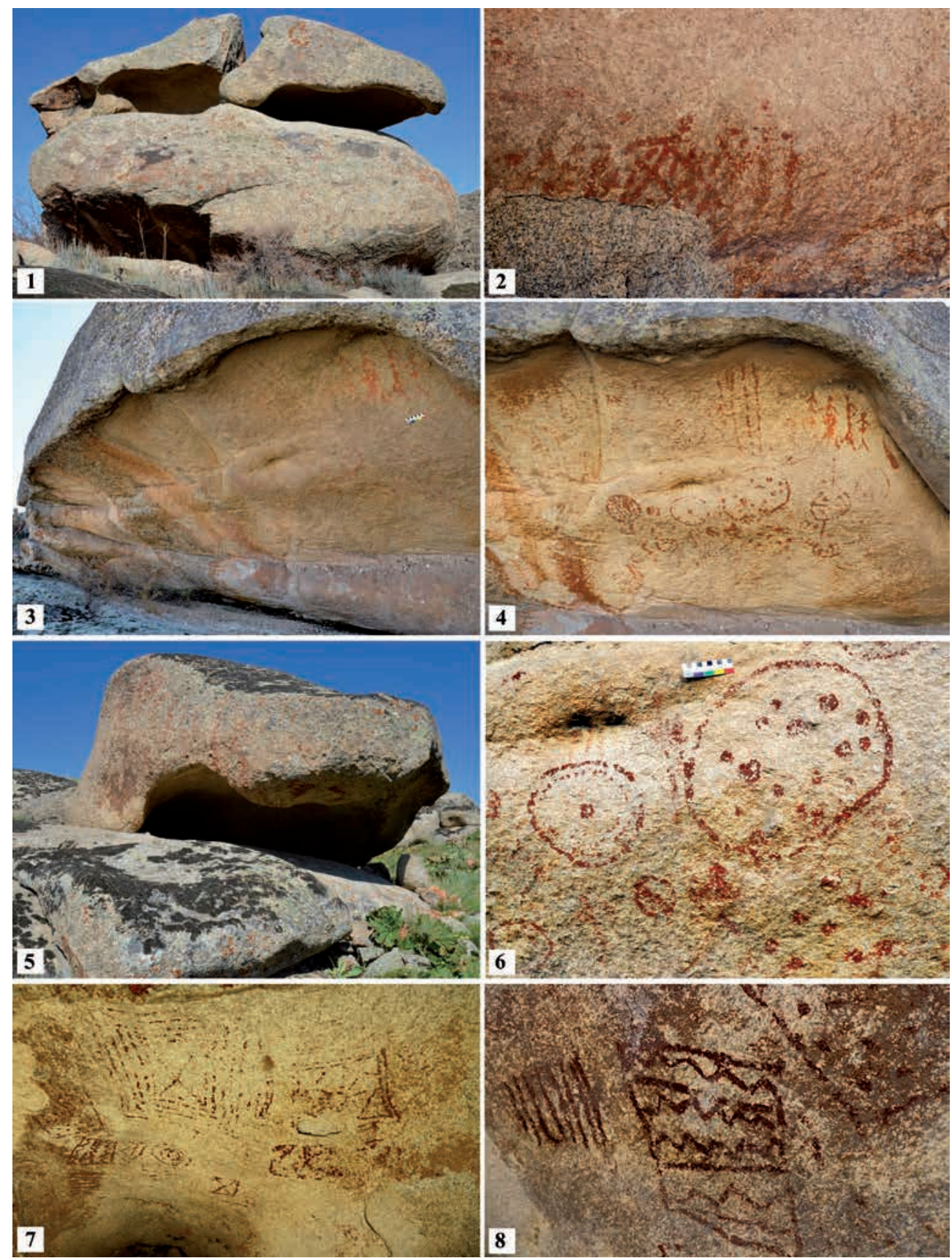

Рис. 4. Росписи скальных навесов: 1 - Шатыртас 7 и 8; 2 - Шатыртас 8; 3, 4, 6 - Шатыртас 12; 5, 7, 8-Шатыртас 13. Фото автора

Fig. 4. Paintings of rock shelters: 1 -Shatyrtas 7 and 8; 2 -Shatyrtas 8; 3, 4, 6-Shatyrtas 12; 5, 7, 8-Shatyrtas 13. Author's photo 


\section{ҚАЗАҚСТАН АРХЕОЛОГИЯСЫ № 3 (9) 2020}

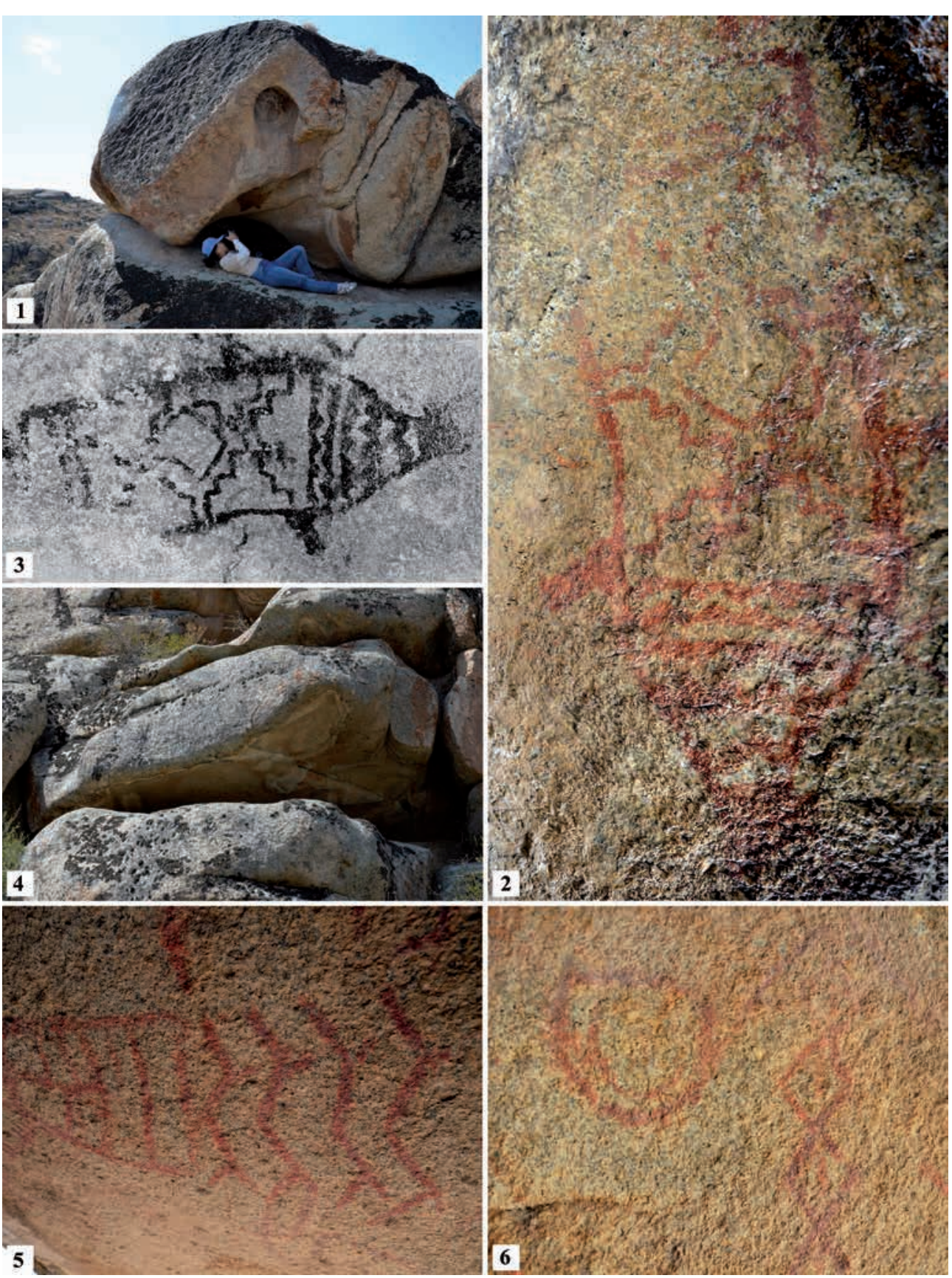

Рис. 5. Росписи гротов: 1, 2, 3-Шатыртас 11; 4, 5, 6-Шатыртас 14. Фото 2 и 3 автора, обработка фотографий - Е.А. Миклашевич

Fig. 5. Paintings of grottoes: 1, 2, 3 -Shatyrtas 11; 4, 5, 6-Shatyrtas 14. Author's photo 2 and 3 processed by E.A. Miklashevich 
тров. В верхней части справа выделяется небольшой отвесный участок, но ниже плоскость под отрицательным углом спускается к основанию скалы. На вертикальной поверхности вырисовываются четыре стоящие рядом антропоморфные фигуры; они выглядят ярче других рисунков, хотя большинство росписей здесь выполнены такой же краской. Почти вся остальная поверхность навеса занята изображениями окружностей, заполненных линиями или рядами точек (рис. 4,6 ); между ними располагаются другие рисунки - концентрические окружности, скопления точек, одиночные и парные зигзаги. Верхнюю часть панно занимают две отдельные группы параллельных волнообразных и прямых линий, между которыми слабо просматриваются остатки каких-то других росписей.

Рисунки исключительно геометрических форм украшают желобчатый свод навеса Шатыртас 13 (рис. 4, 5, $7,8)$, расположенный в верховье примыкающей к ущелью справа эрозионной долины. Вся группа рисунков видна одномоментно с одной точки наблюдения - снаружи у входа, но высота свода позволяет рассматривать отдельные крупные изображения, находясь под сенью просторного навеса (длина 3 м, высота до 1,0 м).

Можно заметить некоторую упорядоченность рисунков: разные по виду фигуры расположены в три ряда, полностью занимая центральную часть свода. Первый ряд от входа образуют три изображения: посредине большая фигура с прямоугольником в центре, разделенным на сегменты отходящими от углов линиями, вокруг которого - пять рядов обрамляющих линий; слева - контур квадрата меньшей величины, внутреннее простран- ство которого заполнено множеством точек, нанесенных без видимого порядка; справа - также подквадратная фигура, контур которой обведен двойной линией, а внутри - усеченный ромб с солярным символом посредине (окружность с 11-ю лучами). Во втором ряду различаются: в центре - три концентрические окружности; слева - в прямоугольной рамке орнаментальный фриз с чередующимися вертикальными отрезками ломанных и прямых линий; справа - фриз с более сложной орнаментальной композицией, но сохранность рисунка хуже. Наконец, последний ряд изображений состоит из двух или трех фигур: девяти параллельных коротких линий; прямоугольника, разделенного линиями на сегменты («конверт»); третья фигура повреждена и плохо различима. Немного ниже и обособленно от других рисунков сохранилась часть еще одного изображения: множество точек, заключенных в квадратную рамку. В глубине навеса на своде и стене заметны красноватые пятна от еще нескольких изображений худшей сохранности. Всего здесь насчитывается более 10 разных фигур, выполненных в основном краской бордового цвета.

Грот Шатыртас 14 (рис. 5, 4) по морфологии и расположению в ландшафте напоминает Шатыртас 11: широкая полость под низким сводом на отвесной скале, на высоте более 5 м над ложем каньона. Лишь малая часть росписей видна от подножия скалы; только находясь внутри грота, можно ознакомиться с живописным панно, украшающим его плоский свод. Всего насчитывается около 20-ти отдельных рисунков: сложных комбинированных фигур, одиночных знаков и одно антропоморфное изображение. 
Здесь нет ни одного изображения, похожего на росписи других памятников долины Сарыбулак. Все комбинированные изображения оригинальны и отличаются даже по набору основных элементов орнамента. Неоднократно используется мотив соединенных вершинами ромбов (в одном случае - с короткими продольными линиями внутри); в двух контурных фигурах основные линии украшены «бахромой»; уникально изображение в виде двух вписанных дуг или полукружий (рис. 5, 6); антропоморфная фигура передана как две совмещенные основаниями трапеции. Одна из фигур с «бахромой» вдоль контура напоминает изображение личины.

Росписи выполнены красками двух цветов - красного и бордового (преобладает); иногда фигуры подновлялись или дорисовывались, при этом использовался бордовый пигмент (рис. 5, 5); дважды фиксируется перекрывание линиями такого цвета деталей изображений, выполненных красной краской. Однако говорить о существенном временном разрыве между созданием тех и других рисунков сложно.

Таким образом, для большинства навесов и гротов с живописью долины Сарыбулак характерны сходный набор красок и приемов украшения полостей разного типа, однако в репертуаре росписей за малым исключением практически нет повторяющихся на разных объектах изображений.

Сравнительный анализ и датировка памятников

На юге Казахстана, в отличие от Сарыарки и Прииртышья, памятники наскальной живописи вплоть до настоящего времени не были известны: открытию росписей в долине Сарыбулак хронологически предшествует только находка красочных рисунков навеса Енбек в долине Каратала [Мерц И.В., Антонов, 2019].

Согласно ранее разработанной автором типологии памятников наскального искусства Центральной Азии [Рогожинский, 2011, с. 30-32, рис. 2], найденные в долине Сарыбулак объекты относятся к подтипу 1.1. как малые скопления красочных и выбитых наскальных рисунков на закрытых поверхностях гротов и навесов, полный обзор которых возможен изнутри полостей и/или снаружи с определенной близкой позиции. Особую подгруппу составляют гроты Шатыртас 11 и 14, где обзор рисунков возможен только изнутри и лежа под сводами скальных полостей. Такая специфическая особенность представляется важным функциональнотипологическим признаком обоих гротов и позволяет в качестве близкой аналогии выделить навесы Сийпанташ на южном склоне Зеравшанского хребта в Узбекистане [Хужаназаров, 2011, с. 322-323, фото 6, 7; Рогожинский, 2008, с. 91-92, рис. 5]. Большинство других объектов, найденных в Сарыбулак, относится к широко распространенному типу памятников, в которых росписи нанесены на участки полостей с расчетом на их осмотр снаружи: гроты П. Л. Драверта, Тесиктас, Акбаур, Теректы и Енбек в Казахстане, навесы и гроты Зараут-камар, Аксакалатасай и Сангижумасай в Узбекистане [Хужаназаров, 2011, с. 321-322] и др.

Наиболее значимой отличительной чертой росписей долины Сарыбулак является преобладание в репертуаре орнаментальных мотивов над другими изображениями, вклю- 
чая знаки, антропоморфные и зооморфные образы. Орнаментальный характер росписей очевиден в декоре гротов Шатыртас 6, 11, 13 и 14. Среди известных памятников Казахстана по этому признаку определенную близость обнаруживают недавно найденные росписи под скальными навесами в горах Калмаккырган на северо-востоке Сарыарки (неопубликованные материалы исследований В. К. Мерца и автора). Однако более всего орнаментальность наскальных росписей выделяет памятники, сосредоточенные в низкогорных районах бассейна Среднего Зеравшана, такие как Сийпанташ и Сангижумасай. На сводах, например, двух навесов Сийпанташ, как и многих полостей Шатыртас, можно видеть сходные геометрические орнаменты; совпадает и палитра полихромных росписей. В целом, своеобразие росписей долины Сарыбулак дает повод к сопоставлению их с материалами культур Средней Азии эпохи энеолита и раннего бронзового века, в которых устойчиво сохранялась традиция изготовления расписной посуды.

Показательным примером служит декоративное панно на козырьке и на своде грота Шатыртас 6. Здесь преобладают разноцветные монохромные изображения при наличии, по меньшей мере, двух полихромных фигур («водоплавающая птица» и шесть волнообразных линий). Подобное разнообразие палитры, а также сочетание черной и темно-красной или бордовой краски в бихромной росписи при широком распространении и посуды с монохромной росписью характерно для керамического комплекса развитого и позднего энеолита (Намазга II и III) культуры Анау на юге Туркменистана [Массон, 1956, с. 298;
Сарианиди, 1965, с. 6]. На Алтын-депе обломки «инокультурного сосуда с трехцветной орнаментацией красным, черным и белым» найдены в строительном горизонте конца позднего энеолита [Кирчо и др., 2008, с. 38, 92 , табл. 106Б: 1]. Очень редко применение белой краски встречается на расписной посуде из Хапуз-депе времени Намазга IV, притом что «роспись белой краской совершенно неизвестна в Туркмении в предшествующее время, зато отмечена для расписной посуды Белуджистана III тыс. до н.э.» [Сарианиди, 1976, с. 88].

Декоративный мотив из нескольких вертикальных, наклонных или горизонтальных волнистых линий, заполняющих фигуры фризов, характерен для расписной посуды развитого энеолита Южного Туркменистана и встречается в монохромной росписи на керамике периодов Саразм I и II [Массон, 1962, с. 12, 23, табл. IV, 31; Исаков, 1991, рис. 70, 3, табл. IV, 8]. Подобный мотив в виде наклонных волнистых линий, заполняющих контур центральной ромбической фигуры, обрамленной несколькими рядами прямых линий, присутствует в росписи керамики времени Намазга III из Кара-депе у Артыка и Ак-депе [Массон, 1960, табл. XXV, 6, 12, 14; Кирчо, 1999, рис. 6, 10]. Своеобразная фигура на своде Шатыртас 6 в виде окружности с бордюром из силуэтных треугольников напоминает вид горловины сосудов, украшенных дополнительным орнаментом на внутренней поверхности венчиков, как на посуде ранней бронзы периода Намазга IV из Ак-депе и Алтын-депе, а также - декор зеркала из погр. 845 на Алтын-депе, украшенного штампованным орнаментом [Сарианиди, 1976, рис. 2, 9; 3, 1; 7, 6; Хронология..., 
2005 , с. 406 , табл. 135,10 , рис. 6,48$]$. Возможно, гравированный орнамент из заштрихованных треугольников вдоль бортика зеркала из местности Джам [Аванесова и др., 2005, рис. 3], несомненно, несущий ту же солярную символику, служит позднейшей реминисценцией данного дизайнерского эксперимента декораторов анауской керамики и металла времени Намазга IV. В ковровой росписи посуды того же периода можно видеть аналогии и вертикальным «елочкам» на козырьке Шатыртас 6, и орнаментальному фризу из ломаных линий под навесом Шатыртас $2[\mathrm{Mассон,} \mathrm{1956,} \mathrm{рис.} \mathrm{6,}$ табл. XXXI, 9, 14].

Уникальная фигура быка из грота Шатыртас 11 представляется особенно информативной: узор на корпусе животного по набору элементов и мотивов орнамента, по композиционной схеме фриза сопоставим с орнаментикой расписной керамики геоксюрского стиля и находит немало аналогий в комплексах времени позднего Намазга II-Намазга III на памятниках Юго-Восточного Туркменистана, а также в ранних комплексах поселения Саразм в верховьях Зеравшана. Вероятный возраст наскальной росписи, учитывая современные данные по хронологии геоксюрского комплекса и ранних слоев Саразма, может оцениваться как конец периода среднего - начало периода позднего энеолита (позднее Намазга II - раннее Намазга III) в пределах ок. 3300-2800/2700 гг. до н.э. или последняя треть IV начало III тыс. до н.э. [Кирчо, 2012; 2017; Раззоков, 2016, с. 91, 95]. Красочные изображения скальных навесов Шатыртас 8 и 13, которые также обнаруживают сходство со многими мотивами и орнаментальными фризами на расписной керамике развитого, позднего энеолита и ранней бронзы Средней Азии, могли создаваться в интервале второй половины IV III тыс. до н.э.

\section{Bblводbl}

Серия гротов и навесов с росписями Шатыртас на сегодняшний день является самым значительным и ярким памятником наскальной живописи Казахстана. В составе обследованной группы скальных полостей определенно выделяются относительно поздние и более ранние объекты, которые характеризуются сходством основного репертуара изображений, общностью мотивов орнамента, набором использовавшихся красок, а также специфическими условиями экспонирования живописи. Среди известных памятников наскальной живописи на территории Казахстана и Средней Азии наибольшее сходство демонстрируют скальные навесы с росписями Сангижумасай, Аксакалатасай в горах Нуратау и Сийпанташ на южном склоне Зеравшанского хребта в Узбекистане. Сходство этих памятников в технике и орнаментике наскальной живописи позволяет связывать те и другие с археологическими культурами энеолита и ранней бронзы Средней Азии, предметный комплекс которых включает посуду, расписанную геометрическим орнаментом.

Неповторимое своеобразие красочных рисунков в гротах и навесах Шатыртас позволяет с датировать древнейшие из них второй половиной IV тыс. до н.э. и отмечать как наиболее вероятную причину столь точного воспроизведения на скалах орнаментации посуды геоксюрского стиля проникновение в этот удаленный от основного ареала район какой-то группы населения анауской культуры. Несомненно, дальнейшее изучение памятников до- 
Pогожинский A.E. Шатыртас: новые открытия наскальной живописи в Юго-Восточном Казахстане

лины Сарыбулак выявит здесь и поселенческие комплексы, оставленные создателями наскальной живописи. Появление в горах Киндыктас, вблизи плодородной Шуской долины, древнеземледельческих поселений могло быть обусловлено близостью одного из самых крупных на юго-востоке Казахстана меднорудных месторождений Шатырколь [Берденов, 2008, с. 52], которое находится буквально в пешей доступности (менее 10 км) от каньона Сарыбулак с удивительными наскальными росписями.

\section{Благодарности}

Автор выражает свою глубокую признательность д. и. н., профессору Г. В. Кану, к. и. н. И. С. Югай и Д. В. Лобанову, принимавшим активное участие в обследовании и документировании памятников долины Сарыбулак в 2019 г. Автор также выражает благодарность Е. А. Миклашевич за любезное содействие в специальной обработке фотоматериалов и Б. С. Бобомуллоеву - за ознакомление c неопубликованными материалами поселения Саразм.

\section{ЛИТЕРАТУРА}

1. Аванесова Н.А., Шайдулаев Ш.Б., Еркулов А. К вопросу о культурной принадлежности джамских древностей эпохи палеометалла // Цивилизации скотоводов и земледельцев Центральной Азии. Бишкек: МИЦАИ, 2005. С. 12-33.

2. Берденов С.А. Казахстанские месторождения меди и олова и их разработка в позднем бронзовом веке // Известия НАН РК. Сер. обществ. наук. 2008. № 1. C. $42-55$.

3. Исаков А.И. Саразм. К вопросу становления раннеземледельческой культуры Зеравшанской долины (раскопки 1977-1983 гг.). Душанбе: Дониш, 1991. 244 с. +4 вкл.

4. Кирчо Л.Б. К изучению позднего энеолита Южного Туркменистана (основы классификации расписной керамики и неопубликованные материалы поселения Акдепе). СПб.: Петербургкомстат, 1999. 120 с.

5. Кирчо Л.Б. Север и Юг - встреча на Зеравшане // Культуры степной Евразии и их взаимодействие с древними цивилизациями. СПб.: ИИМК РАН, «Периферия», 2012. Кн. 2. С. 284-287.

6. Кирчо Л.Б. К датировке геоксюрского комплекса (новые данные из Алтындепе в Южной Туркмении) // Записки ИИМК РАН. 2017. № 16. С. 35-51.

7. Кирчо Л.Б., Коробкова Г.Ф., Массон В.М. Технико-технологический потенциал энеолитического населения Алтын-депе как основа становления раннегородской цивилизации. Труды ИИМК РАН. Т. XXVIII. СПб.: Европейский Дом, 2008. 370 с.

8. Массон B.M. Расписная керамика Южной Туркмении по раскопкам Б.А. Куфтина // Труды ЮТАКЭ. Т. VII. Ашхабад: типография АН ТССР, 1956. С. 291373.

9. Массон В.М. Кара-депе у Артыка (в свете раскопок 1955-1957 гг.) // Труды ЮТАКЭ. Т. Х. Ашхабад: изд-во АН ТССР, 1960. С. 319-463.

10. Массон В.М. Памятники развитого энеолита Юго-Западной Туркмении. САИ. Б3-8. М.-Л.: Наука, 1962. Ч. ІІ. 20 с., 30 табл.

11. Мери И.В., Антонов М.А. Грот Енбек с наскальными росписями в окрестностях г. Талдыкоргана // Отан тарихы. 2019. № 2 (86). С. 200-214. 
12. Раззоков Ф.А. Строительные комплексы древнеземледельческого поселения Саразм в IV-III тыс. до н. э. СПб.: Невская Книжная Типография, 2016. 248 с.

13. Рогожинский A.E. О современных задачах археологии наскального искусства Казахстана и Средней Азии // АЭАЕ. 2008. № 4 (36). С. 83-94.

14. Рогожинский A.E. Памятники наскального искусства как культурные ландшафты // Сборник материалов международного семинара-тренинга по историкокультурному наследию стран СНГ (г. Алматы, 19-23 сентября 2011 г.). Алматы: «Аруна», 2011. С. 28-46.

15. Сарианиди В.И. Памятники позднего энеолита Юго-Восточной Туркмении. САИ. Б3-8. Ч. IV. М.: Наука, 1965. 81 с., 27 табл.

16. Сарианиди В.И. Материальная культура Южного Туркменистана в период ранней бронзы // Первобытный Туркменистан. Ашхабад: Ылым, 1976. С. 82-111.

17. Хронология эпохи позднего энеолита - средней бронзы Средней Азии (погребения Алтын-депе) / Массон В.М., Березкин Ю.Е. (ред.) Труды ИИМК РАН. T. XVI. СПб.: «Нестор-История», 2005. 540 с.

18. Хужаназаров М.M. Памятники наскального искусства Узбекистана // Наскальное искусство в Центральной Азии. Тематическое исследование / Жан Клотт (ред.). Париж: ИКОМОС, 2011. С. 313-328.

\section{REFERENCES}

1. Avanesova, N. A., Shajdulaev, Sh. B., Erkulov, A. 2005. In: Civilizacii skotovodovi zemledelcev Centralnoj Azii (Civilizations of pastoralists and agriculturists in Central Asia). Bishkek: IICAS Publ., 12-33 (in Russian).

2. Berdenov, S. A. 2008. In: Izvestiya NAN MON RK (Proceeding of the National Academy of Sciences Ministry of the Education and Sciences). 1 (254). 42-55 (in Russian).

3. Isakov, A. I. 1991. Sarazm. K voprosu stanovlenija rannezemledelcheskoj kultury Zeravshanskoj doliny (raskopki 1977-1983 gg.) (Sarazm. To the question of the formation of early farming culture of the Zeravshan valley (excavations 1977-1983)). Dushanbe: "Donish" Publ. (in Russian).

4. Kircho, L. B. 1999. K izucheniju pozdnego jeneolita Juzhnogo Turkmenistana (osnovy klassifikacii raspisnoj keramiki i neopublikovannye materialy poselenija Ak-depe) (To the study of the Late Eneolithic of Southern Turkmenistan (the basis for the classification of painted pottery and unpublished materials from the Ak-Depe settlement)). Saint Petersburg: Peterburgkomstat (in Russian).

5. Kircho, L. B. 2012. In: Kultury stepnoj Evrazii i ih vzaimodejstvie s drevnimi civilizacijami (Cultures of steppe Eurasia and its interaction with ancient civilizations). Saint Petersburg: "Periferija" Publ., 284-287. Book 2 (in Russian).

6. Kircho, L. B. 2017. In:Zapiski Instituta istorii materialnoj kultury RAN(Transactions of the Institute for the History of Material Culture), 16, 35-51 (in Russian).

7. Kircho, L. B., Korobkova, G. F., Masson, V. M. 2008. Tehniko-tehnologicheskij potencial jeneoliticheskogo naselenija Altyn-depe kak osnova stanovlenija rannegorodskoj civilizacii (The technical and technological potential of the Eneolithic population of AltynDepe as the basis of the rise of an early urban civilization). Proceedings of IIMK RAS. XXVIII. Saint Petersburg: "Evropejskij Dom” Publ. (in Russian).

8. Masson, V. M. 1956. In: Trudy Uzhno-Turkmenistanskoi Arheologicheskoi Kompleksnoi Ekspedicii (Materials of Southern Turkmenian Archaeological Complex Expedition). VII. Ashhabad. 291-373 (in Russian).

9. Masson, V.M. 1960. In Trudy Uzhno-Turkmenistanskoi Arheologicheskoi Kompleksnoi Ekspedicii (Materials of Southern Turkmenistan Archaeological Complex Expedition). X, 319-463 (in Russian). 
10. Masson, V. M. 1962. Pamjatniki razvitogo jeneolita Jugo-Zapadnoj Turkmenii (Monuments of the Middle Eneolithic of South-West Turkmenistan). Moscow-Leningrad: "Nauka" Publ. (in Russian).

11. Merz, I. V., Antonov, M. A. 2019. In: Otan tarihy (Homeland history), 2 (86), 200-214 (in Russian).

12. Razzokov, F. A. 2016. Stroitelnye kompleksy drevnezemledelcheskogo poselenija Sarazm v IV-III tys. do n. e. (Building complexes of the ancient agricultural Sarazm settlement in the 4th - 3rd millennia BCE). Saint Petersburg: "Nevskaja Knizhnaja Tipografija" Publ. (in Russian).

13. Rogozhinskiy, A. E. 2008. In Arheologija, etnografija $i$ antropologija Evrazii (Archeology, Ethnography and Anthropology of Eurasia), 4 (36), 83-94 (in Russian).

14. Rogozhinskiy, A. E. 2011. In Sbornik materialov mezhdunarodnogo seminaratreninga po istoriko-kulturnomu naslediju stran SNG (Almaty, 19-23 sentjabrja 2011 g.) (The collection of materials of the international training seminar on the historical and cultural heritage of the CIS countries (Almaty, 19-23 September, 2011). Almaty: "Aruna" Publ. 28-46 (in Russian).

15. Sarianidi, V. I. 1965. Pamjatniki pozdnego jeneolita Jugo-Vostochnoj Turkmenii (Monuments of the Late Eneolithic of Southeast Turkmenistan). IV. Moscow: "Nauka" Publ. (in Russian).

16. Sarianidi, V. I. 1976. In Pervobytnyj Turkmenistan (Prehistoric Turkmenistan). Ashhabad: "Ylym" Publ., 82-111 (in Russian).

17. Hronologija jepohi pozdnego jeneolita - srednej bronzy Srednej Azii (pogrebenija Altyn-depe) (The chronology of the Late Eneolithic - Middle Bronze Ages in Central Asia (Burials of Altyn-Depe)). 2005. / Masson, V. M., Berezkin, Ju. E. (ed.). Trudy Instituta istorii materialnoj kultury RAN (Works of the Institute for the History of Material Culture). XVI. Saint Petersburg: "Nestor-Istoriya" Publ. (in Russian).

18. Huzhanazarov, M. M. 2011. In Naskalnoe iskusstvo Centralnoj Azii. Tematicheskoe issledovanie (Rock Art in Central Asia. A Thematic study). ICOMOS. Paris: ICOMOS Publ.. 313-328 (in Russian).

\footnotetext{
Мүдделер қақтығысы туралы ақпаратты ашу. Автор мүдделер қақтығысының жоқтығын мәлімдейді. / Раскрытие информации о конфликте интересов. Автор заявляет об отсутствии конфликта интересов. / Disclosure of conflict of interest information. The author claim no conflict of interest.

Мақала туралы ақпарат / Информация о статье / Information about the article.

Редакцияға түсті / Поступила в редакцию / Entered the editorial office: 20.08.2020.

Рецензенттер макұлдаған / Одобрено рецензентами / Approved by reviewers: 23.08.2020.

Жариялауға қабылданды / Принята к публикации / Accepted for publication: 29.08.2020.
} 